\title{
Mediação Cultural e Formação de Públicos: 0 caso da AJAGATO e da Revista Cena's em Vila Nova de Santo André (Alentejo Litoral)
}

Cultural Mediation and the Training of Audiences: The case of AJAGATO and Cena's Magazine in Vila Nova de Santo André (Alentejo Litoral)

Nuno Correia de Brito - Universidade Autónoma de Lisboa NIP-C@M ICNOVA/FCSH NOVA nbrito@autonoma.pt https://doi.org/10.26619/978-989-9002-14-2.9

\begin{tabular}{|c|c||c|}
\hline Recebido / Received & Aceite / Accepted & $\begin{array}{c}\text { Publicado / Published } \\
\text { 15.06.2020 }\end{array}$ \\
25.06 .2020 & 15.01 .2021 \\
\hline
\end{tabular}

Como citar este capítulo / How to quote this chapter:

Brito, N. (2021). "Mediação Cultural e Formação de Públicos: O caso da AJAGATO e da Revista Cena's em Vila Nova de Santo André (Alentejo Litoral)". In Lourenço, J. \& Lopes, P. (eds.), Comunicação, Cultura e Jornalismo Cultural. Lisboa: NIP-C@M \& UAL, (pp. 188-214), disponível em https://repositorio.ual.pt/handle/11144/4757. DOI https://doi.org/10.26619/978-989-9002-14-2.9

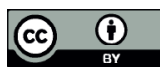




\section{Resumo}

O presente artigo tem como objetivo fazer uma análise sobre a ação de uma associação, enquanto mediador cultural para a área do teatro, na região do Alentejo Litoral. Recorrendo a análise documental de um período de 20 anos, à analise de conteúdo de um projeto editorial, assim como à história de vida de um dos seus principais agentes, foi possível realizar um estudo de caso, concluindo e é possível afirmar com clareza que a organização e os seus protagonistas são os responsáveis em grande parte pela formação de públicos qualificados para a área cultural, em geral, e do teatro, em particular, naquela região. 


\section{Abstract}

This article aims to make an analysis about the action of an association, as a cultural mediator for the theater domain, in the region of Alentejo Litoral (Portugal). Using the documental analysis of a 20-year period, the content analysis of an editorial project, as well as the life history of one of its main actors, it was possible to carry out a case study, concluding and it is possible to state clearly that the organization and its protagonists are largely responsible for the training of qualified audiences for the cultural domain, in general, and theater, in particular, in that region. 
O centro urbano de Santo André, atualmente Cidade de Vila Nova de Santo André, foi inicialmente concebido para albergar todos aqueles que viriam contribuir para transformar o "megalómano"1 projeto em realidade. Já em 1971, as primeiras linhas do plano começaram a ser implementadas com a criação do Gabinete da Área de Sines (GAS), através do Decreto-Lei no270/71 de 19 de junho, durante a governação de Marcello Caetano, que the outorga poderes que se sobrepõem aos dos municípios.

Sete dias antes da "revolução", a 18 de Abril de 1974, o Diário de Notícias noticiava o empréstimo de "cerca de um milhão de contos" da Caixa Geral de Depósitos, para a construção da refinaria de Sines ${ }^{2}$. Estava lançada a "primeira pedra" daquela que viria a ser a primeira cidade criada de raiz em Portugal no século XX. Com a criação do projeto industrial no Alentejo Litoral, os concelhos de Sines e Santiago do Cacém viriam a conhecer transformações económicas, culturais e sociais profundas.

É perante este cenário que nos posicionamos, quando ambicionamos descrever e analisar uma realidade que começou a ser definida há mais de 40 anos. Após o 25 de Abril de 1974, alterações profundas na sociedade portuguesa operaram nas suas diferentes dimensões. O processo de descolonização é descrito, por muitos autores, como sendo o fenómeno social de maior impacto no nosso país, fruto das novas visões político-adminis-

1 Madeira, J. (2007/2008). A Cidade Nova. Revista Cena's, no7, pp.32-33

2 Diário de Notícias (1974, Abril, 18). A Caixa Geral de Depósitos emprestou à Petrosul cerca de um milhão de contos. p.1 
trativas, após a revolução. Muitas daquelas pessoas que vieram, os apelidados "retornados" das antigas colónias ultramarinas, à época uma palavra de conotação negativa, encontraram em Santo André e no empreendimento industrial de Sines o seu novo projeto de vida, quer de forma passageira e temporária ou, como sabemos hoje, "para ficar".

Pensemos num lugar onde confluem pessoas de muitas proveniências, diferentes culturas e valores. Este lugar poderia ser Santo André na sua fase inicial. No meio do "areal", forma como muitas vezes é descrito, nasce um centro urbano, construído por blocos de cimento, muitos destes complexos habitacionais desenhados por grandes nomes da nossa melhor arquitetura contemporânea. Uma urbe desenhada a régua e esquadro, com a capacidade alojar 100 mil pessoas, a poucos metros da praia, em plena duna, entre o pinhal. Prevê rodovias amplas, poucas vias pedonais e um jardim central que funciona como o coração do local. Sem grandes infraestruturas, no início era um "não-lugar" na aceção de Marc Augé, onde muitas identidades confluíam, uma massa anónima sem raízes, em movimento passageiro de "rota migratória".

Começam então a surgir os problemas de como integrar todas aquelas pessoas. O plano urbanístico rigoroso denominava os "bairros" identificando-os pelo número de fogos (habitações) que comportavam. Esta toponímia fria, deu lugar aos batismos populares, na tentativa de conferir identidade a um lugar estéril, mas repleto de potencialidades: "Lagartixa", "Pôr do Sol", "Pe- 
trogal", "Serrotes", "Panteras", "Azul”, “Liceu", "Torres", entre outros ${ }^{3}$.

A escola é vista como elemento agregador, gerador de coesão social, promotor de desenvolvimento social e cultural, como fatores impulsionadores de tudo o resto. A escola preparatória torna-se, assim, um autêntico "oásis" num imenso deserto de areia, onde os contornos identitários se vão construindo, com efeitos numa população que começa a estabelecer-se aos poucos como uma comunidade. Este artigo, revela como a escola e os professores se constituem como elementos estruturais e estruturantes da sociedade.

Falemos de educação e de mediação cultural. De acordo com o Professor Mário Primo, no seu artigo intitulado "O Teatro e a Cidade" no no 15 da revista Cena's ${ }^{4}$, refere que,

"De início, vivia-se "portas adentro, ninguém era de cá e muitos pareciam estar, apenas em trânsito, porém os filhos desenvolveram laços de pertença fortes a este lugar. Aos poucos a população foi-se enraizando e começaram a surgir algumas estruturas associativas de natureza local, desportiva e cultural, muitas delas a partir da dinâmica das escolas, ou nelas sedeadas".

Este artigo tem como proposta partir do conceito de mediação aplicado aos bens culturais e artísticos, mas igualmente à educação, tendo em vista a análise da ação da associação AJAGATO

3 Madeira, J. (2007/2008). A Cidade Nova. Revista Cena's, no7, pp. 32-33.

4 Primo, M. (2020, Fevereiro). O Teatro e a Cidade. Revista Cena's, n15, pp.16-17. 
e das suas iniciativas em Vila Nova de Santo André (no concelho de Santiago do Cacém), nomeadamente a programação teatral e a publicação da revista Cena's, num recorte temporal de cerca de 20 anos.

O conceito de mediação cultural tem vindo a ser tratado no âmbito das Ciências da Comunicação e da Informação, pois compreende em si a génese, a manutenção e a reprodução de elementos estruturantes da cultura, cuja existência só é possível através de fenómenos comunicacionais. Neste sentido, J. DavalIon enfatiza o papel deste domínio científico no estudo dos aspetos simbólicos, que sustentam aqueles processos: "Pour être clair : poser que les sciences de l'information et de la communication sont déjà en train de concourir à une exploration du fonctionnement symbolique de notre société..." (2003: 52).

Corroborando esta ideia, Jean Caune (1999) considera imprescindível investigar os fenómenos de mediação cultural, porque o verdadeiro lugar da cultura constitui-se pelas interações individuais e, no plano subjectivo, o universo de significação que qualquer um pode construir na relação com o outro. A cultura, por este ponto de vista, representa a mediação que permite e constrói a história social (1999: 121). Neste processo estão envolvidas relações sociais e simbólicas, materiais e imaginárias, que dependem, necessariamente, da mediação (1999: 105). Aludindo a Roger Silverstone (2005: 34), a mediação é o processo segundo o qual os seres humanos colocam em circulação os significados. 
Tendo em vista a formação de públicos para as artes e para a cultura, especialmente no que toca ao teatro, a AJAGATO tem vindo a estabelecer-se naquela região alentejana como um dos principais agentes de educação e desenvolvimento neste domínio, com uma ação independente e com um contributo relevante para as políticas culturais do concelho, revelando o seu trabaIho de mediação, levando o teatro a populações, que de outra maneira, não conseguiriam ter facilmente acesso.

O estudo recorre a fontes documentais, nomeadamente a relatórios da associação; à análise de conteúdo da revista Cena's, enquanto veículo de comunicação por excelência das atividades e dos propósitos da AJAGATO, história de vida do professor Mário Primo, assim como a análise da evolução dos espetadores de teatro naquela região.

“O teatro em Santo André foi estimulado pela concepção singular do projeto portuário, industrial e urbano do Gabinete da Área de Sines e, simultaneamente, teve impacto na identidade cultural da população que aqui se instalou, cujo interesse pelas Artes de Palco constitui um património invulgar da cidade" ${ }^{5}$.

É possível apresentar a ação deste professor de Educação Visual, que ali se fixou no final dos anos 70, ex-aluno de Arquitetura da ESBAL (a antiga escola que deu lugar às Faculdades de Arquitetura e de Belas Artes da Universidade de Lisboa), proveniente de Almada, e do projeto que tem vindo a

5 Primo, M. (2020, Fevereiro). O Teatro e a Cidade. Revista Cena's, no15, pp.16-17 
desenvolver nesta localidade como causa-efeito, num verdadeiro processo de mediação cultural e que em muito contribuiu para criar e desenvolver públicos para a área das Artes e da Cultura, especialmente no que toca às artes performativas e ao teatro em particular.

Tendo a escola como epicentro de todo este processo, a sua abertura ao meio, a interação entre a escola e a comunidade, constituem os pilares principais. Num lugar sem história, nem raízes, os desafios eram muitos. Tirar partido das suas características geográficas, especialmente do facto de estar a poucos metros da maior extensão de praia da Europa, o lugar era propício à prática desportiva, como o surf, a exploração da natureza, a canoagem, etc. A construção de pavilhões multiusos, permitiam o desenvolvimento de modalidades desportivas (futebol de salão, hóquei em patins, ginástica acrobática, patinagem artística).

Em termos culturais, o panorama era mais complicado pela inexistência de museus, bibliotecas, auditórios ou outras estruturas de fruição de bens culturais. A escola preparatória tenta preencher esta lacuna, propondo atividades de complemento curricular, como a pintura, a música ou o teatro. Neste contexto, nasce em 1983 o Teatril, um grupo de teatro infantil de cariz escolar, com o objetivo de propor um espaço extracurricular aos alunos pela mão do professor Mário Primo. Rapidamente este professor se apercebeu das particularidades e vantagens que a mediação teatral poderia aportar para a 
educação de crianças e da respetiva comunidade, não só por constituir uma área charneira onde poderão confluir várias linguagens artísticas, mas também por assentar na didática da disciplina que leciona, enquanto educação da sensibilidade e do gosto para as artes, colocando em prática metodologias como o trabalho de projeto, envolvendo alunos, pais e professores, extensível a toda a comunidade envolvente.

Após um curso ministrado em 1986 por Joaquim Benite, fundador do Teatro de Almada, e que envolveu professores e alunos, inclusivamente o professor Mário Primo e os alunos integrantes do Teatril, surge com a inauguração das instalações ímpares da escola secundária de Santo André, que incluía um extraordinário auditório, em 1988, o GATO S.A., um grupo de teatro com pretensões de ir mais além do contexto escolar, que segundo o seu mentor,

"nessa altura estava tudo por fazer e a precaridade geral
estimulou-nos a enfrentar as dificuldades, fazendo da
insatisfação um motor criativo que contrariasse o estigma de
viver num local incaracterístico e sem história num impulso
para participar na criação de uma cidade especial." ${ }^{\text {n }}$

O GATO S.A. vai tomando forma pela direção do Professor Mário Primo e pelos alunos que compunham o elenco fundador, sendo que a sua ação começa a sentir "reverberação" não só na comunidade escolar, mas também em toda a comunidade

6 Primo, M. (2020, Fevereiro). O Teatro e a Cidade. Revista Cena's, nำ15, pp.16-17 
de Santo André, tendo encontrado o seu lugar e propósito na comunidade envolvente, com legitimidade pelas suas propostas, encenações, atividades pedagógicas e de formação com alunos e professores, atividades de animação cultural como a organização de festivais e mostras de teatro, levando o nome de Santo André mais longe:

"Os jovens atores assumiram-se como embaixadores da escola e da região e viram frequentemente reconhecido o seu talento e empenho em inúmeras ocasiões, algumas delas ao mais alto nível: Encontros Nacionais de Teatro, participação na Expo 98 e em festivais no país e no estrangeiro ..."7

Poucos anos mais tarde, no âmbito da introdução da disciplina de Oficina de Expressão Dramática nos curriculae do ensino secundário, o professor Mário Primo passa a lecionar neste nível de ensino e torna-se, assim, possível continuar a desenvolver a sua atividade de mediação teatral na escola e na comunidade, agora integrando outros projetos pedagógicos. Nasce, desta forma, a Teatroteca, um espaço dedicado às atividades de contexto pedagógico, envolvendo alunos e professores, mas aberto a toda a comunidade.

O projeto GATO S.A. apesar de estar associado à escola secundária por inerência às suas instalações, integra agora a Teatroteca, enquadrando e legitimando a sua ação na comunidade. Todavia, com o desenvolvimento e crescimento da

7 Primo, M. (2020, Fevereiro). O Teatro e a Cidade. Revista Cena's, no15, pp.16-17 
atividade do GATO S.A., acrescido da necessidade de integrar de alguma forma os jovens membros que se viram forçados a sair de Santo André para prosseguimento de estudos universitários, assim como enquadrar de forma legal as atividades e justificar os apoios monetários que recebiam para a sua ação, houve a necessidade da criação da AJAGATO (Associação Juvenil Amigos do GATO), em 1999. A criação da entidade jurídica, constituída por jovens que de alguma forma estavam ou estiveram no passado relacionados com o grupo de teatro, abre as portas para um caminho que se quer evolutivo e, desta forma, poder aspirar a um nível superior no que toca a apoios e à qualidade dos projetos.

Numa região onde parcas são as condições para a fruição de espetáculos de artes performativas, a associação define como um dos principais domínios de ação, a criação, requalificação e manutenção de infraestruturas e equipamentos apropriados para a apresentação espetáculos de qualidade profissional, reunindo condições para apresentar os espetáculos do GATO S.A, bem como receber companhias em itinerância e os participantes nas Mostras de Teatro, com todos os padrões de qualidade e segurança exigidos, quer a nível de instalações, quer a nível de recursos técnicos e materiais. De facto, a AJAGATO tem vindo desde a sua fundação criar condições para a apresentação e fruição deste tipo de espetáculos, contanto, atualmente, com o considerável património e um investimento na criação e melhoria das condições e equipamentos que ultrapassam já os 100 mil euros, segundo o seu responsável. 
Perante todo um caminho consolidado na área do teatro e educação, constituindo-se como o principal agente de mediação cultural na área teatral da região (Concelhos de Santiago do Cacém, Sines, Odemira, Grândola e Alcácer do Sal), com um importante trabalho realizado junto das escolas com implicações óbvias no desenvolvimento de públicos qualificados e na literacia para a artes, em grande parte através de projetos de educação formal, não formal e informal, surgem os dois grandes projetos da AJAGATO e do GATO S.A.: A Mostra de Teatro de Santo André, que mais tarde se torna num dos mais importantes e reputados festivais de teatro portugueses, dando lugar a um programa de dimensão internacional com a vinda de importantes nomes e companhias estrangeiros; e a revista Cena's, uma publicação cultural que surge com a evolução do seu veículo de comunicação por excelência, o boletim informativo "Aqui há Gato", e que pretende ser antes de mais um elemento de ligação entre os atuais e antigos membros do grupo, assim como colaboradores e toda a comunidade, veiculando artigos de carácter cultural, de forma a abarcar de maneira transversal várias áreas e linguagens, como o Teatro, a Música, a Literatura, as Viagens, a Etnografia, a Arquitetura, a História, o Cinema, as Artes Visuais, entre outras.

A Mostra de Teatro de Santo André constituiu um dos maiores projetos levados a cabo pela AJAGATO na região alentejana, no sentido de proporcionar à população o contacto com grupos e companhias teatrais e as suas respetivas criações e trabalhos. De certa forma, a programação do evento obedeceu a padrões 
de qualidade e estéticos definidos pelas linhas orientadoras da associação e pelo seu mentor, o professor Mário Primo: "O teatro é Cultura e a Mostra é uma escola do espetador e de cidadania"8. O trabalho realizado ao longo de 18 edições, desde 1999 até 2017, seguiu um trajeto evolutivo, quer a nível do número de companhias e espetáculos participantes, como o nível de sessões oferecidas, bem como a abrangência territorial e de público. Todavia, no que toca aos meios, recursos financeiros e técnicos, constatou-se em vários relatórios as dificuldades atravessadas pela organização, que se manifestaram insuficientes, num ritmo inconstante, sem qualquer critério e ao sabor da sorte, pois, em alguns anos foram atribuídas quantias por entidades que em anos posteriores não se mantinham, prejudicando em grande parte a manutenção e a constância da qualidade e exigência que um evento desta natureza requer.

Este projeto, conseguiu legitimar-se aos olhos das entidades locais e junto da população, tendo por isso crescido de ano para ano, com o esforço de muito trabalho voluntário e boa vontade de todos. Mas um evento de qualidade requer um nível de profissionalização que era impossível de conseguir, pela falta de recursos humanos e de um financiamento que $o$ permitisse. Os projetos levados a cabo pela AJAGATO contam essencialmente com o tempo do professor Mário Primo que tem integrado essas atividades no âmbito da lecionação, enquanto apoio a projetos de complemento curricular, assim como alguns estagiários e profissionais financiados por programas

8 Ajagato (2016). Relatório da 17ạ Mostra Internacional de Teatro de Santo André, p.11 
do IPJ (Instituto Português da Juventude) e do IEFP (Instituto de Emprego e Formação Profissional), estes últimos com vínculos algo precários e inconstantes. É notória esta necessidade revelada em vários relatórios e os sucessivos pedidos para alocar mais professores, assim como o aumento de horas para o projeto e a redução de horário para o professor titular que permita o acompanhamento das atividades, pois, de ano para ano, a situação afigura-se diferente. Após anos de déficit nos balanços e a falta e inconstância nos apoios financeiros, técnicos e de recursos humanos, e de avisos recorrentes às entidades, a AJAGATO decidiu pôr termo ao projeto em 2017, a braços com uma dívida de 12.000 euros após a organização da 18a Mostra Internacional de Teatro de Santo André.

É de realçar todo o trabalho realizado, espelhado nos números de espetadores que tiveram contacto com o festival de ano para ano, com uma marcada preocupação de chegar a vários públicos, quer a nível de gosto e opões estéticas, quer a nível etário ou características socioculturais. A programação compreendia a área da formação com workshops realizados por profissionais, a oferta de espetáculos de qualidade profissional, as "abaladiças" que compreendiam sessões após os espetáculos que serviam de discussão sobre as opções e reflexão interpretativa sobre a obra, os espetáculos para a infância e outras atividades de carácter cultural e artístico como exposições de pintura e fotografia ou música. 
Após a análise documental da AJAGATO e da Teatroteca, foi possível chegar ao quadro (Fig.1) que de seguida apresentamos e que revela dados pertinentes para compreender o efeito que o projeto Mostra de Teatro teve na região, quanto ao número de espetadores, associado ao número de espetáculos, que de ano para ano variava, e de um financiamento, que nunca foi constante:

\begin{tabular}{|c|c|c|c|c|}
\hline Mostra no & ano & espetáculos & público & custo \\
\hline 3 mostra & 2002 & 12 & 1600 & $10532,92 €$ \\
\hline 4 mostra & 2003 & 13 & 2100 & $11588,67 €$ \\
\hline 5 mostra & 2004 & 11 & 2039 & $15391,07 €$ \\
\hline 6 mostra & 2005 & 15 & 2450 & $18024,87 €$ \\
\hline 7 mostra & 2006 & 17 & 2210 & $19487,96 €$ \\
\hline 8 mostra & 2007 & 26 & 4153 & $34246,30 €$ \\
\hline 9 mostra & 2008 & 26 & 4153 & $40033,52 €$ \\
\hline 10 mostra & 2009 & 15 & 3411 & $27.582,00 €$ \\
\hline 11 mostra & 2010 & 21 & 4067 & $37.003,00 €$ \\
\hline 12 mostra & 2011 & 16 & 4656 & $43315,00 €$ \\
\hline 13 mostra & 2012 & 12 & 2774 & $31335,00 €$ \\
\hline 14 mostra & 2013 & 24 & 3361 & $32807,00 €$ \\
\hline 15 mostra & 2014 & 15 & 7020 & $41.660,00 €$ \\
\hline 16 mostra & 2015 & 14 & 5565 & $38659,00 €$ \\
\hline 17 mostra & 2016 & 16 & 5597 & $43.125,00 €$ \\
\hline 18 mostra & 2017 & 15 & 5332 & $52808,50 €$ \\
\hline
\end{tabular}

Figura 1 Quadro comparativo sobre público e investimento da Mostra de Teatro 
De acordo com o relatório da 18a Mostra Internacional de Teatro de Santo André ${ }^{9}$ é possível ler em jeito de conclusão que,

\begin{abstract}
"Ao longo das 18 edições recebemos 86 companhias de teatro diferentes, tanto nacionais como estrangeiras e 231 peças de teatro, selecionadas com grande exigência qualitativa e o propósito muito claro da formação de um público conhecedor e exigente e não apenas o seu entretenimento".
\end{abstract}

Segundo o quadro apresentado (Fig.1) é possível constatar que, de uma forma geral, os custos/ investimento seguem uma tendência de crescimento, assim como os números referentes aos espetadores, embora com algumas oscilações nos anos de 2011 e 2012. Do ano 2002 ao ano 2017, o projeto envolveu mais de 268 espetáculos, 60.488 espetadores nas sessões e $256.762,31$ mil euros de investimento total.

Um outro projeto que contribui largamente para o propósito da AJAGATO é a revista Cena's, uma publicação de âmbito local na área cultural, mas com impacto a nível nacional e, especialmente, junto dos agentes que atuam neste domínio. Desta forma, o projeto que nasce do desenvolvimento de um boletim informativo, dá lugar a um projeto editorial muito bem concebido e estruturado em 2003, e que conta até à data com preciosas contribuições de reconhecidos profissionais e entidades do setor cultural (Fig.2). Embora com uma periodicidade errante, motivada pela disponibilidade

9 Ajagato (2016). Relatório da 18a Mostra Internacional de Teatro de Santo André 
dos participantes e dos recursos, é um projeto que tem mantido uma linha de atuação coerente quanto ao conteúdo e forma, graças a orientações editoriais precisas organizadas por seções e rubricas que se mantêm em todos os números, assim como um design da autoria do antigo membro e ator do GATO SA, Pedro Dias.

As escolhas editoriais revelam os objetivos e propósitos da associação enquanto mediador cultural da região. Após análise de conteúdo realizada a todos os números da publicação, incluindo os editoriais, é possível afirmar a constante preocupação em envolver todos os membros e antigos elementos do grupo, contribuir para o principal objetivo de promover as artes e a cultura de uma maneira geral, e o teatro de forma particular. Além disso, é de notar algumas opiniões nos editorais acerca das políticas culturais em Portugal, enquadradas num pensamento ideológico de esquerda, quer pelo discurso, quer pelos símbolos e temáticas veiculados nas mensagens. É possível constatar no relatório anual de atividades conferente ao ano letivo de $2002 / 2003^{10}$, a introdução do projeto da publicação:

"Preparação de uma pequena revista, eventualmente com uma
periodicidade semestral, que corresponda à evolução do bole-
tim "Aqui há gato!", alargando-o à participação de outros co-
laboradores e com a inclusão de artigos de reflexão sobre as
práticas e outras problemáticas culturais.A revista constituiu
a grande novidade deste ano e foi um objectivo plenamente
atingido! Se alguma diferença houve quanto às previsões, foi de 10 Ajagato (2002/2003). Relatório de atividades, p.15 
terem sido largamente ultrapassadas as expectativas quanto à nossa capacidade de concretização deste projecto".

Relativamente ao projeto editorial, após a análise do documento preparado para o efeito pela AJAGATO e onde define as linhas orientadoras, é possível ler-se nos pontos 2 e 3 do referido documento (2003: 1$)^{11}$ :

“2. Trata-se de editar uma publicação que possa funcionar como elemento de ligação dos membros do grupo e dos amigos, de que uma parte se encontra associada na AJAGATO.

Desse ponto de vista, torna-se relevante potenciar as capacidades e vontades de uma vasta rede de pessoas, jovens na sua grande maioria, que mantendo ou tendo mantido uma participação activa, quer de ligação directa quer de apoio, sob multifacetadas formas, às actividades do GATO, continuam a ser como que o primeiro anel de inserção do grupo na comunidade. Isto significa criar um espaço de participação acrescida de muitos desses elementos, uns mantendo ainda actividade de expressão dramática, outros, diversificando interesses e oportunidades, criando noutras áreas artísticas e culturais ou desenvolvendo sensibilidades.

A revista pretende configurar um local de confluência e sinergia desses interesses, sensibilidades e expressões.

3. Mas trata-se também alargar a sua área de intervenção, convocando à colaboração, à reflexão, ao debate e à polémica outros grupos e agentes culturais, formais e informais existentes

11 Ajagato (2003), Projeto da Revista Cena's, pp.1-2 
na zona e com quem o GATO mantém relações de amizade e cooperação; grupos de teatro, naturalmente, amadores e profissionais, mas também de música ou orientados para a escrita criativa, para a imagem ou para qualquer outra forma de criação.

A revista pretende configurar igualmente um espaço de debate, de troca de experiências, de divulgação de iniciativas, correntes estéticas, perspectivas e orientações diversas no campo cultural."

Ainda no documento referente ao projeto da revista já citado, os públicos para a publicação são definidos (2003: 2):

"Membros do grupo de teatro GATO S.A.; associados na AJAGATO; membros e amigos de grupos culturais formais e informais da zona ou com quem o GATO mantém relações de amizade e cooperação; agentes, criadores e mediadores culturais em diferentes áreas e com diferentes projectos culturais, professores e educadores com preocupações de intervenção cultural nas escolas ou em associações da zona, população potencialmente interessada nestas temáticas". 


\begin{tabular}{|c|c|c|c|c|c|}
\hline $\begin{array}{l}\text { Revista } \\
\text { no }\end{array}$ & Data & $\begin{array}{l}\text { № } \\
\text { pag }\end{array}$ & Rubricas/ secções & Autores & Tiragem \\
\hline 1 & $\begin{array}{l}\text { primavera/ } \\
\text { verão } \\
2003\end{array}$ & 24 & $\begin{array}{l}\text { Bocas de cena (entrevista } \\
\text { João Mota); Descritas; } \\
\text { Ouvimos; Lemos; Vemos; } \\
\text { Em Cena; Teóricas e Práticas } \\
\text { (Teatro ao Largo como um } \\
\text { baile numa noite de verão); } \\
\text { a preto e branco; a preto e } \\
\text { branco; teóricas e práticas; } \\
\text { Photohistórias; Aqui há gato }\end{array}$ & $\begin{array}{l}\text { Rita Amado; } \\
\text { Lúcia Palminha; } \\
\text { Hugo Lopes; } \\
\text { Maria José } \\
\text { Botelho; Nuno } \\
\text { Silva; Steve } \\
\text { Johnson; Liliana } \\
\text { Nascimento; } \\
\text { André Príncipe; } \\
\text { Luís Cruz; João } \\
\text { Madeira; }\end{array}$ & 1000 \\
\hline 2 & $\begin{array}{l}\text { Outono/ } \\
\text { inverno } \\
2003\end{array}$ & 24 & $\begin{array}{l}\text { Bocas de cena (entrevista } \\
\text { com João Brites); } \\
\text { Cenários;descritas;vemos; } \\
\text { ouvimos,; lemos; em cena; } \\
\text { Teóricas e Práticas; a preto e } \\
\text { Branco; Teóricas e Práticas; } \\
\text { Photohistórias (João } \\
\text { Madeira); Aqui há Gato }\end{array}$ & $\begin{array}{l}\text { Rita Amádo; João } \\
\text { Lobe; } \\
\text { z.dado; Nuno } \\
\text { Silva; Hugo } \\
\text { Lopes; Rogério } \\
\text { Carrola; Carlos } \\
\text { Seixas; Nuno } \\
\text { Cintrão; Jaime } \\
\text { Salazar Sampaio; } \\
\text { João Madeira }\end{array}$ & 1000 \\
\hline 3 & $\begin{array}{l}\text { Primavera/ } \\
\text { verão } \\
2004\end{array}$ & 28 & $\begin{array}{l}\text { Bocas de cena (entrevista } \\
\text { com Hélder Costa); } \\
\text { cenários; descritas; 10 acto; } \\
\text { vemos, ouvimos ; lemos; em } \\
\text { cena; teóricas e práticas; a } \\
\text { preto e branco; teóricas e } \\
\text { práticas; teóricas e práticas; } \\
\text { photohistórias, Aqui há gato }\end{array}$ & $\begin{array}{l}\text { Rita Amado; } \\
\text { Nuno Silva; Maria } \\
\text { José Botelho; } \\
\text { Joana Rita; André } \\
\text { Pacheco; Carlos } \\
\text { Seixas; Hugo } \\
\text { Lopes; João Lobe; } \\
\text { Z. dado; Eduarda } \\
\text { Dionísio; Nuno } \\
\text { Cera; Teresa } \\
\text { Rita Lopes; } \\
\text { Isabel Silva; João } \\
\text { Madeira }\end{array}$ & 1000 \\
\hline 4 & $\begin{array}{l}\text { Outono/ } \\
\text { Inverno } \\
2004\end{array}$ & 28 & $\begin{array}{l}\text { Bocas de cena (entrevista } \\
\text { com Joaquim Benite); } \\
\text { patrimónios; descritas; } \\
\text { vemos; ouvimos; lemos; } \\
\text { em cena; cenários; teóricas } \\
\text { e práticas; a preto e } \\
\text { branco; teóricas e práticas; } \\
\text { photohistórias, aqui há gato }\end{array}$ & $\begin{array}{l}\text { Rita Amado; } \\
\text { Carlos Sobral; } \\
\text { Martins } \\
\text { Quaresma; } \\
\text { Rogério Carrola; } \\
\text { Luís Manuel } \\
\text { Filipe; Hugo } \\
\text { Lopes; Maria } \\
\text { Afonsp; z. dado; } \\
\text { nuno silva; Julieta } \\
\text { Aurora Santos; } \\
\text { rui martins; } \\
\text { helder guerreiro; } \\
\text { João Madeira }\end{array}$ & 1200 \\
\hline
\end{tabular}




\begin{tabular}{|c|c|c|c|c|c|}
\hline 5 & $\begin{array}{l}\text { Primavera/ } \\
\text { verão } \\
2005\end{array}$ & 32 & $\begin{array}{l}\text { Bocas de cena (entrevista } \\
\text { com Jorge Silva Melo); } \\
\text { patrimónios; descritas; } \\
\text { teóricas e práticas; vemos, } \\
\text { ouvimos, lemos; em cena; } \\
\text { quadradinhos; cenários; } \\
\text { teóricas e práticas; a preto e } \\
\text { branco; teóricas e práticas; } \\
\text { photohistórias; Aqui há gato }\end{array}$ & $\begin{array}{l}\text { Carlos Mota; } \\
\text { Carlos Sobral; } \\
\text { Martins } \\
\text { Quaresma; } \\
\text { Paula Barroso; } \\
\text { Luís Cruz; Luís } \\
\text { Manuel Filipe; } \\
\text { Hugo Lopes; } \\
\text { Maria Afonso; } \\
\text { Filipe Sousa e } \\
\text { Carlos Seixas; } \\
\text { David Pádua e } \\
\text { Edgar Raposo; } \\
\text { Nuno Silva; Tiago } \\
\text { Bartolomeu } \\
\text { Costa; Júlia } \\
\text { Garcia; Dora } \\
\text { Isabel Batalim; } \\
\text { João Madeira }\end{array}$ & 1200 \\
\hline 6 & $\begin{array}{l}\text { Primavera } \\
\text { verão } \\
2006\end{array}$ & 36 & $\begin{array}{l}\text { Bocas de cena (entrevista } \\
\text { com Miguel Seabra); } \\
\text { Teóricas e Práticas; } \\
\text { descritas; cenas da } \\
\text { memória; vemos; } \\
\text { ouvimos; lemos; em cena; } \\
\text { quadradinhos; cenários; } \\
\text { teóricas e práticas; } \\
\text { patrimónios; a preto e } \\
\text { branco; photoshistórias; } \\
\text { aqui há gato; }\end{array}$ & $\begin{array}{l}\text { Rita Amado; } \\
\text { Manuel Graça } \\
\text { Dias; Isabel } \\
\text { Mora e Matos } \\
\text { Costa; Luís Cruz; } \\
\text { Luís Manuel } \\
\text { Filipe; Hugo } \\
\text { Lopes; Maria } \\
\text { Afonso; z.dado; } \\
\text { David Pádua e } \\
\text { Edgar Raposo; } \\
\text { Nuno Silva; Rita } \\
\text { Wengorovius } \\
\text { e Alberto } \\
\text { Nico; Carlos } \\
\text { Sobral; Martins } \\
\text { Quaresma } \\
\text {; Felizarda } \\
\text { Barradas; João } \\
\text { Madeira }\end{array}$ & 1400 \\
\hline
\end{tabular}




\begin{tabular}{|c|c|c|c|c|c|}
\hline 7 & $\begin{array}{l}\text { Inverno } \\
2006 / 2007\end{array}$ & 36 & $\begin{array}{l}\text { bocas de cena (entrevista } \\
\text { com Teresa Ricou); } \\
\text { vemos; teóricas e } \\
\text { práticas; descritas; cenas } \\
\text { da memória ; ouvimos } \\
\text {; lemos; quadradinhos } \\
\text {; cenários ; teóricas e } \\
\text { práticas; crónica; a preto } \\
\text { e branco; photohistórias ; } \\
\text { patrimónios; aqui há gato }\end{array}$ & $\begin{array}{l}\text { Tomás } \\
\text { Cabral; Ana } \\
\text { Barroso; Tiago } \\
\text { Bartolomeu } \\
\text { Costa; Margarida } \\
\text { Fonseca Santos } \\
\text { e André Lança } \\
\text { (ilustração) / } \\
\text {; José Carlos } \\
\text { Guinote ; Luís } \\
\text { Filipe; Hugo } \\
\text { Lopes; Maria } \\
\text { Afonso; David } \\
\text { Pádua e Edgar } \\
\text { Raposo; Nuno } \\
\text { Silva; Mário da } \\
\text { Costa; Carlos } \\
\text { Fragateiro; Duda } \\
\text { (fotos) Tília } \\
\text { (texto); João } \\
\text { Madeira; Carlos } \\
\text { Sobral, Martins } \\
\text { Quaresma }\end{array}$ & 1500 \\
\hline 8 & $\begin{array}{l}\text { Fevereiro } \\
2007\end{array}$ & 12 & $\begin{array}{l}\text { Bocas de cena } \\
\text { (entrevista com José } \\
\text { Mário Branco); cenas da } \\
\text { memória; testemunhos; } \\
\text { photohistórias }\end{array}$ & $\begin{array}{l}\text { João Mota; } \\
\text { Viriato Teles; } \\
\text { Helder Costa e } \\
\text { José Jorge Letria; } \\
\text { João Madeira }\end{array}$ & 1500 \\
\hline $9 / 10$ & SD (2008) & 40 & $\begin{array}{l}\text { Bocas de cena (entrevista } \\
\text { a Patrick Hayter); Teóricas } \\
\text { e Práticas ; Crónica ; } \\
\text { Quadradinhos ; Lemos ; } \\
\text { Vemos ; Cenários ; Crónica } \\
\text {; Crónica ; Bocas de cena } \\
\text { (entrevista com Nola Rae); } \\
\text { Patrimónios ; Teóricas } \\
\text { e Práticas ; Ouvimos; A } \\
\text { Preto e Branco ; Crónica ; } \\
\text { Photohistórias ; aqui há gato }\end{array}$ & $\begin{array}{l}\text { Steve Johnston; } \\
\text { José Rui Martins ; } \\
\text { Luís Filipe ; Nuno } \\
\text { Cintrão; Maria } \\
\text { Afonso; Hugo } \\
\text { Lopes; Nuno } \\
\text { Silva; Mário } \\
\text { Primo; Luis Cruz } \\
\text {; Steve Johnston } \\
\text {; Martins } \\
\text { Quaresma; } \\
\text { Associação } \\
\text { PédeXumbo; } \\
\text { Rui Gaudêncio } \\
\text { Texto Tília; Jordi } \\
\text { Permanyer ; João } \\
\text { Madeira }\end{array}$ & 2000 \\
\hline
\end{tabular}




\begin{tabular}{|c|c|c|c|c|c|}
\hline 11 & SD (2009) & 32 & $\begin{array}{l}\text { Cenários; Bocas de cena } \\
\text { (entrevista a Mário Barradas) } \\
\text { Crónica; Quadradinhos; } \\
\text { Ouvimos; Lemos ; Bocas de } \\
\text { cena (entrevista a Fernanda } \\
\text { Lapa) Crónica; Teóricas e } \\
\text { Práticas; A Preto e Branco ; } \\
\text { Patrimónios; Photohistórias; } \\
\text { aqui há gato }\end{array}$ & $\begin{array}{l}\text { Ana Carolina; } \\
\text { Tomás Cabral; } \\
\text { Fernando Malão; } \\
\text { André Pacheco } \\
\text {; Z.dado ; Maria } \\
\text { Afonso ; Carlos } \\
\text { Mota ; Luís } \\
\text { Manuel Filipe; } \\
\text { Mário Moutinho; } \\
\text { Henrique } \\
\text { Silva; Martins } \\
\text { Ouaresma: João }\end{array}$ & 2000 \\
\hline 12 & $\begin{array}{l}\text { SD (2010) } \\
{ }^{*} \text { sem data } \\
\text { registada }\end{array}$ & 36 & $\begin{array}{l}\text { Bocas de Cena (Entrevista } \\
\text { com António Chainho); } \\
\text { Vemos ; Ouvimos ; Lemos } \\
\text {; Lemos ; Ecos ; Teóricas e } \\
\text { Práticas ; Teóricas e Práticas } \\
\text {; Crónica ; Descritas ; } \\
\text { Quadradinhos ; A Preto e } \\
\text { Branco ; Photohistórias ; } \\
\text { Patrimónios; Aqui Há Gato }\end{array}$ & $\begin{array}{l}\text { Carlos Mota ; } \\
\text { Hugo Lopes; } \\
\text { Z.dado; Maria } \\
\text { Afonso; Joaquim } \\
\text { Gonçalves; } \\
\text { Sebastiana } \\
\text { Fadda ; José } \\
\text { Russo; Teatro } \\
\text { do Montemuro } \\
\text {; Luís Filipe ; } \\
\text { Isabel Moura ; } \\
\text { André Pacheco } \\
\text {; Zé Mónica ; } \\
\text { João Madeira } \\
\text {; António } \\
\text { Quaresma }\end{array}$ & 2000 \\
\hline 13 & $\begin{array}{l}\text { SD (2011) } \\
\text { Maio } \\
\text { *sem data } \\
\text { registada }\end{array}$ & 17 & $\begin{array}{l}\text { Bocas de Cena (Entrevista } \\
\text { com Luís Miguel Cintra); } \\
\text { Vemos; Ouvimos; Lemos; } \\
\text { Vemos ; Teóricas e Práticas ; } \\
\text { Teóricas e Práticas ; Crónica } \\
\text {; Descritas ; Quadradinhos } \\
\text {; A Preto e Branco ; } \\
\text { Photohistórias ; Patrimónios } \\
\text {; Aqui Há Gato }\end{array}$ & $\begin{array}{l}\text { Carlos Mota; } \\
\text { Raquel Schefer } \\
\text {; Hugo Lopes; } \\
\text { Valter Hugo } \\
\text { Mãe ; Maria } \\
\text { Afonso; Z.dado } \\
\text {; Ana Barroso; } \\
\text { Quadricultura } \\
\text { Renato Ferracini; } \\
\text { Luís Filipe ; } \\
\text { João Tordo ; } \\
\text { André Pacheco; } \\
\text { Alípio Padilha; } \\
\text { João Madeira; } \\
\text {; António } \\
\text { Quaresma }\end{array}$ & 2000 \\
\hline
\end{tabular}




\begin{tabular}{|c|c|c|c|c|c|}
\hline 14 & $\begin{array}{l}\text { Janeiro } \\
2013\end{array}$ & 32 & $\begin{array}{l}\text { Bocas de Cena (Homenagem } \\
\text { A Joaquim Benite) Ouvimos; } \\
\text { Lemos; Teóricas e Práticas } \\
\text {; Teóricas e Práticas ; Ecos ; } \\
\text { Crónica ; Poemas Inéditos } \\
\text {; Quadradinhos ; A Preto } \\
\text { e Branco ; Photohistórias ; } \\
\text { Patrimónios ; Aqui Há Gato }\end{array}$ & $\begin{array}{l}\text { Sarah } \\
\text { Adamopoulos; } \\
\text { Hugo Lopes } \\
\text {; Pedro Rosa } \\
\text { Mendes; Maria } \\
\text { Afonso ; Isabel } \\
\text { Silva ; Carina } \\
\text { Infante do } \\
\text { Carmo ; Luís } \\
\text { Filipe ; Pedro } \\
\text { Carreira de Jesus } \\
\text {; André Pacheco } \\
\text {; Felizarda } \\
\text { Barradas ; } \\
\text { João Madeira } \\
\text {; António } \\
\text { Quaresma }\end{array}$ & 2000 \\
\hline 15 & $\begin{array}{l}\text { Fevereiro } \\
2020\end{array}$ & 36 & $\begin{array}{l}\text { Bocas de Cena (Entrevista } \\
\text { a João Lourenço); Vemos; } \\
\text { Ouvimos; Lemos; Teóricas } \\
\text { e Práticas ; Aqui há Gato; } \\
\text { Teóricas e Práticas ; Crónica } \\
\text {; Descritas; Quadradinhos } \\
\text { André Pacheco; A Preto } \\
\text { e Branco; Photohistórias; } \\
\text { Patrimónios }\end{array}$ & $\begin{array}{l}\text { Nuno Brito; } \\
\text { Isabel Silva; } \\
\text { Celso Martins } \\
\text {; Joaquim } \\
\text { Gonçalves; } \\
\text { Baal17; Mário } \\
\text { Primo; José } \\
\text { António Falcão; } \\
\text { Luís Filipe ; Alice } \\
\text { Brito; André } \\
\text { Pacheco; Víctor } \\
\text { Horta; João } \\
\text { Madeira; António } \\
\text { Quaresma }\end{array}$ & 1500 \\
\hline 16 & $\begin{array}{l}\text { Fevereiro } \\
2020\end{array}$ & 12 & $\begin{array}{l}\text { (homenagem a José Mário } \\
\text { Branco, por altura da sua } \\
\text { morte) O Zé Mário no teatro } \\
\text { do mundo; José Mário } \\
\text { Branco: Algumas notas José } \\
\text { Mário Branco "Que Fado É } \\
\text { Esse Afinal?"; José Mário } \\
\text { Branco e o GAC: “Vi tanta } \\
\text { esperança andar à solta..." ; } \\
\text { Zé Mário, o bom gigante }\end{array}$ & $\begin{array}{l}\text { Cucha } \\
\text { Carvalheiro; } \\
\text { Hugo Castro e } \\
\text { Ricardo Andrade; } \\
\text { João Carlos } \\
\text { Callixto; João } \\
\text { Madeira; Hélder } \\
\text { Costa }\end{array}$ & 1500 \\
\hline
\end{tabular}

Figura 2 Quadro de análise de conteúdo da Revista Cena's 


\section{Conclusões}

Os dados analisados levam-nos a afirmar seguramente que existe uma ação de causa-efeito da atividade desenvolvida pela AJAGATO na região do Litoral Alentejano, particularmente nos concelhos de Santiago do Cacém e Sines, no aspeto relacionado com o acesso e fruição de teatro. É notória a influência das suas ações e projetos naquele território, que muito se evidenciam nos hábitos e números de público de assistência em espetáculos teatrais. Pelo que podemos afirmar que a formação de públicos qualificados para atividades culturais e para o teatro, naquela região, dependem fortemente das ações e projetos levados a cabo pela AJAGATO e que o seu papel no processo de mediação cultural é sem dúvida uma referência e um exemplo a seguir.

O processo de mediação desenvolvido a partir de instrumentos como ações pedagógicas junto de alunos e professores, organização de festivais de teatro, apoio à criação e produção de espetáculos, assim como a publicação da revista Cena's tem conseguido obter resultados muito significativos na criação de públicos qualificados para a fruição de bens culturais e do teatro em particular naquela região.

\section{Bibliografia}

Ajagato (2003). Projeto da Revista Cena's, pp.1-2

Ajagato (2016). Relatório da 17ạ Mostra Internacional de Teatro de Santo André, pp.10-11 
Caune, J. (1999). Pour Une Ethique de La Mediation. Le sens des pratiques culturelles, Sain-Martin-d'Hères. (Isère): Pug.

Davallon, J. (2003). La médiation : la communication en procès?. MEI Médiation et information, 19, pp. 37-59.

Diário de Notícias (1974, Abril, 18). A Caixa Geral de Depósitos emprestou à Petrosul cerca de um milhão de contos. Diário de Notícias, p. 1.

Madeira, J. (2007/2008). A Cidade Nova. Revista Cena's, no7, pp.32-33.

Primo, M. (2020, Fevereiro). O Teatro e a Cidade. Revista Cena's, no15, pp.16-17.

Quintela, P. (2012). Estratégias de mediação cultural: Inovação e experimentação no Serviço Educativo da Casa da Música. Revista Crítica de Ciências Sociais [Online], 94 | 2011, consultado o 14 novembro 2019.

Silverstone, R. (2005). Por que estudar a mídia, 2a edição. São Paulo: Edições Loyola. 